\title{
Informação e trabalho na sociedade capitalista contemporânea
}

\author{
Edilene Maria da Silva \\ Universidade Federal de Pernanbuco - UFPE, Brasil \\ Hamilton Rodrigues Tabosa \\ Universidade Federal do Ceará - UFC, Brasil \\ Williams Santos \\ Edvaldo Carvalho Alves \\ Universidade Federal da Paraíba - UFPB, Brasil
}

\section{REVIEW}

\begin{abstract}
Resumo
O artigo discute questões relativas às mudanças ocorridas no mundo do trabalho informacional (relações homem instrumentos/equipamentos, homem-sociedade) a partir de considerações sobre o avanço tecnológico da atualidade e suas relações com o capitalismo. Apresenta reflexões sobre a evolução das teorias administrativas e a produção de software e ilustra como a reificação do trabalho informacional foi conduzida de acordo com os ditames das tecnologias de informação e comunicação e dos modelos gerenciais.
\end{abstract}

Palavras-chave

Informação ; Trabalho ; Reificação do trabalho ; Trabalho informacional

\section{Information and work in contemporary capitalist society}

\begin{abstract}
The article discusses issues relating to changes in the world of informational labor (relations man - instruments / equipment, man-society) from considerations about the technological advancement of today and its relationship with capitalism. It presents reflections on the evolution of administrative theories and software production and it illustrates how the reificação of informational work was conducted in accordance with the opinions of the information and communication technologies and management models.
\end{abstract}

Keywords

Information; Work ; Reification work ; Informational labor

\section{Introdução}

Historicamente, o trabalho foi considerado como uma atividade aviltante, sendo destinada apenas a pessoas escravizadas e aos grupos sociais mais pobres das sociedades. Somente no século XV o trabalho perdeu essa característica pejorativa, devido à filosofia do Protestantismo, que o considerava não como punição, mas como oferenda a Deus, e como um fator que enobrece o homem, sendo capaz de fazê-lo ascender social e economicamente. Após a Revolução Industrial, as relações de trabalho escravo/servil foram substituídas pelo trabalho assalariado, socialmente valorizado.

A Sociologia do Trabalho interessa-se pelo estudo das transformações do mundo do trabalho - desde a manufatura artesanal, passando pelo trabalho nas indústrias e chegando ao trabalho abstrato. Outra de suas preocupações são as relações do trabalho com as mudanças sociais causadas na família, na cultura e na política. 
Já a partir das últimas décadas do século $X X$, a introdução de novos temas no mundo do trabalho (como o impacto das tecnologias da informação e da comunicação) abrem novas perspectivas para a crítica e a pesquisa no campo sociológico. Nossa intenção, neste trabalho, é trazer à reflexão questões que gravitam o trabalho informacional na sociedade capitalista contemporânea, que tem como matéria-prima, e também como produto, ou seja, como mercadoria, a informação.

Este texto apresenta reflexões sobre a evolução das teorias administrativas e a produção de software e ilustra como a reificação do trabalho informacional foi conduzida de acordo com os ditames das tecnologias de informação e comunicação e dos modelos gerenciais. Este trabalho é fruto de uma revisão bibliográfica ensejada na disciplina Sociologia da Informação, do Programa de Pós-Graduação em Ciência da Informação da Universidade Federal da Paraíba.

\section{Revoluções tecnológica e gerencial}

Desde o início do século XX o mundo tem passado por profundas mudanças. Assistimos a duas guerras mundiais, mudanças de centro de poder, emergência de novas lideranças econômicas mundiais, revolução das tecnologias e comunicações, o aumento da produtividade industrial e agrícola e da urbanização (TENÓRIO, 2009). Essas transformações foram fortemente impactadas pelo desenvolvimento e aplicação das tecnologias de informação e comunicação em diversos setores da sociedade, como a produção de bens e serviços, educação, saúde e outros.

As tecnologias de informação e comunicação (TIC) revolucionaram o setor industrial durante o último século como antes não se havia visto, contudo, seu impacto vai além, ao também contribuir para (r)evolução das teorias administrativas de forma a expropriar do operário não apenas as habilidades físicas, mas também as cognitivas, proporcionando ao capitalismo novas formas de continuidade.

No início do século passado as teorias de Frederick Winslow Taylor sobre o redesenho do trabalho para aumentar a eficiência influenciaram os modos de gestão e perdura até hoje. (MAXIMIANO, 2008). Seus estudos sobre tempo e movimento tinham como objetivo analisar as unidades básicas do trabalho, eliminando os tempos "mortos" e aperfeiçoando os movimentos dos trabalhadores. Suas ideias foram aprimoradas por Henry Ford ao criar a linha de montagem, que elevou ao máximo os dois princípios da produção em massa, que é a fabricação de produtos não diferenciados em larga escala; peças padronizadas e trabalhador especializado.

Isso provocou uma divisão técnica do trabalho vertical e rígida, na qual a concepção e execução ficavam a cargo de profissionais distintos e com qualificação específica. O uso da informação nesse período tornava-se necessário para aferir a produção dos operários e elaborar estratégias que promovessem o aumento da produtividade e, por conseguinte, da competitividade. Cabia ao operário apenas operar a máquina e realizar atividades repetitivas que não demandavam informações - com caráter constante e inovador.

Contudo, as duas guerras mundiais mudaram esse cenário. Após e mesmo durante a II Guerra Mundial muitas tecnologias foram desenvolvidas para promover o desenvolvimento de bens e serviços e a produção, disseminação e uso da informação. A partir da nova configuração econômica mundial, os países perceberam a importância da informação como recurso estratégico para o desenvolvimento e a inovação, embora se ressalte que isso não aconteceu em todos os países simultânea e homogeneamente.

As teorias administrativas também foram se adequando ao novo cenário. O Japão, destruído após o fim da II Guerra, iniciou uma corrida para recuperar sua economia e a indústria foi uma das principais responsáveis. Esse setor japonês não contava com recursos materiais, humanos e tecnológicos para concorrer com outros países, a exemplo dos Estados Unidos, então, criou um novo modelo gerencial que eliminava cargos intermediários e privilegiava o conhecimento dos operários para solucionar problemas na fase produtiva. Isso permitiu uma nova divisão técnica do trabalho, o que não representou necessariamente melhores condições para o trabalhador.

Foi atribuída ao trabalhador japonês a responsabilidade pela produção mais eficiente, a manutenção das máquinas e do espaço de trabalho, incutindo-Ihe a ideia de responsabilidade pelo que desenvolve e entrega ao cliente. As ideias desenvolvidas pelo Sistema Toyota de Produção intensificam a racionalidade do trabalho. Nesse modelo o operário precisava de informações não somente sobre sua produção, mas sobre as máquinas que operam e processo produtivo.

A partir da década de 1970 a teoria administrativa foi fortemente influenciada pelo modelo japonês de administração. Pela Europa se espalhou a ideia de padronização por meio da International Organization for 
Standardization (ISO) - conjunto de normas que estabelece requisitos que auxiliam a melhoria dos processos internos, maior capacitação dos colaboradores, monitoramento do ambiente de trabalho, verificação da satisfação dos clientes, colaboradores e fornecedores, num processo contínuo de melhoria do sistema de gestão da qualidade.

O advento das tecnologias de informação e comunicação derruba barreiras geográficas, temporais e espaciais. O mundo globalizado capitalista exige constante adaptabilidade e flexibilidade das organizações para lidar com as incertezas do mercado. As mudanças no mundo corporativo acontecem rapidamente, o ambiente é instável, as tecnologias se tornam obsoletas, os métodos já não atendem os objetivos organizacionais. E aí acontece um fato importante: as organizações percebem que o capital intangível, ou seja, as pessoas, são a chave para responder as essas incertezas, são elas que detêm as capacidades cognitivas de apreender, interpretar e dar sentido a informação.

As organizações percebem que precisam mudar a forma como fazem a gestão das pessoas e criam estratégias para minimizar o conflito com os operários. Surgem as ideias acerca de flexibilização, integração e reconhecimento pelo trabalho intelectual, estímulo a cooperação e compartilhamento como forma de otimizar o trabalho e o tempo do trabalhador. São criados termos, ou melhor, construídos social e historicamente, como capital intelectual, gestão do conhecimento, aprendizagem organizacional, administração participativa com objetivo de inserir os trabalhadores na "Era do conhecimento".

Todavia, se constituíram em estratégias apenas para manter os operários produzindo mais em menos tempo, e mantendo-os alienados dos meios de produção e do próprio contexto em que esta produção se realiza.

\section{A informação e o trabalho informacional}

É predominante no mundo dos negócios o entendimento da informação sob a visão utilitarista, como recurso que contribui para a produtividade e competitividade. A informação é útil e oportuna quando serve para apoiar atividades operacionais e estratégicas e gerar conhecimento que, por sua vez, se transforme em valor tangível para as organizações. Em alguns momentos a informação é um recurso em outros significa mercadoria/produto final, dependendo do contexto social e da necessidade e/ou do objetivo da organização.

Alguns autores que utilizam da lógica das teorias administrativas para estudar a informação como Choo (2006), Davenport (1998) e Beal (2009) compartilham da ideia da informação como recurso estratégico que precisa ser retida, compilada, analisada, interpretada, partilhada e novamente reorganizada para geração de novos conhecimentos e tomada de decisão num processo contínuo. E para isso os trabalhadores precisam constantemente se submeter aos ditames da tecnologia e do mercado para desenvolver o dito "trabalho informacional" tão valorizado para perenidade do sistema econômico capitalista.

A informação como coisa nos leva a refletir a informação como algo que pode ser descrito, representado e transferido de um indivíduo a outro, de uma organização a outra. Esse processo de transferência situado num dado tempo e contexto social engloba diversas relações, por exemplo, poder e informação. Isso nos leva a algumas indagações: $O$ indivíduo que controla a informação pode exercer poder sobre aqueles que dela precisam? O indivíduo que realiza os processos de análise e interpretação exerce poder sobre aquele que não realiza tais processos?

Os trabalhadores informacionais, que atuam como intermediários da informação entre os níveis operacionais e estratégicos das organizações são envolvidos por metas e objetivos que permeiam sua atividade (e que não foram necessariamente escolhidos por eles), e inconscientemente, reproduzem o discurso do grupo dominante, o que torna o trabalho alienado e reificado?

Essa relação entre poder e informação é evidenciada nos estudos desenvolvidos pela Ciência da Informação. A compreensão da informação como coisa traz em seu bojo conceitos provenientes das teorias administrativas, sem negar sua importância, mas questionando seus limites referentes à informação entendida como recurso ou mercadoria que apenas evidencia "o aparente", instigam outras e diversas reflexões sobre aspectos políticos, econômicos e sociais que estão subjacentes aos processos de gestão da informação, a manutenção do capital e da exploração do trabalho, inclusive, o informacional. 


\section{A coisificação do trabalho informacional}

Quando falamos das transformações que experimentamos no que diz respeito aos processos de comunicação e de acesso à informação trazidas pelo desenvolvimento das relações entre a informática e as telecomunicações, normalmente lembramos da facilidade do uso dos artefatos tecnológicos, da rapidez na comunicação e transferência de dados, do encurtamento de distâncias, da "derrubada" de fronteiras geográficas, da inclusão informacional, dentre outras benéfices inevitavelmente atribuídas ao advento das tecnologias de informação e comunicação. No entanto, nossa sociedade presencia também outros aspectos - os negativos, alienações e abstrações - que podem escapar à observação do sujeito menos atento e mais maravilhado.

O "trabalho informacional", que pode vir a ser considerado como mais sofisticado e menos alienante (considerando que o trabalhador tem acesso à informação durante a própria execução da atividade laboral), genericamente considerado como trabalho dentro da perspectiva capitalista, não foge à lógica do capital e também sujeita o trabalhador à exploração, muito embora isso se dê também de forma mais sutil e "sofisticada". Por trabalho informacional entendamos aquele em que se utiliza a informação como insumo, matéria-prima, para a geração de uma mercadoria também em forma de informação, ou seja, uma mercadoria imaterial, pois, conforme Wolf (2009, p. 90):

Essa é a grande novidade trazida pela tecnologia digital: a possibilidade de se manipular e transformar informações tal como outrora se fazia com matérias-primas de dimensão material, o que permite ao capitalismo de hoje transformar e explorar mercadorias não só no plano material, mas também no imaterial.

O posicionamento de Wolf na referida obra é notoriamente marxista, razão pela qual trazemos de Marx (1974) um conceito de mercadoria, de modo que possamos melhor apreender os argumentos da autora: mercadoria é tudo aquilo que é produzido pelo trabalho humano e colocado no mercado para ser comercializado, sendo que muitas vezes a mercadoria é produzida já com a finalidade de ser vendida.

Dessa forma, vemos que a informação tanto é matéria-prima como produto, provocando transformações em todo o ciclo do trabalho informacional, conforme a Figura 1:

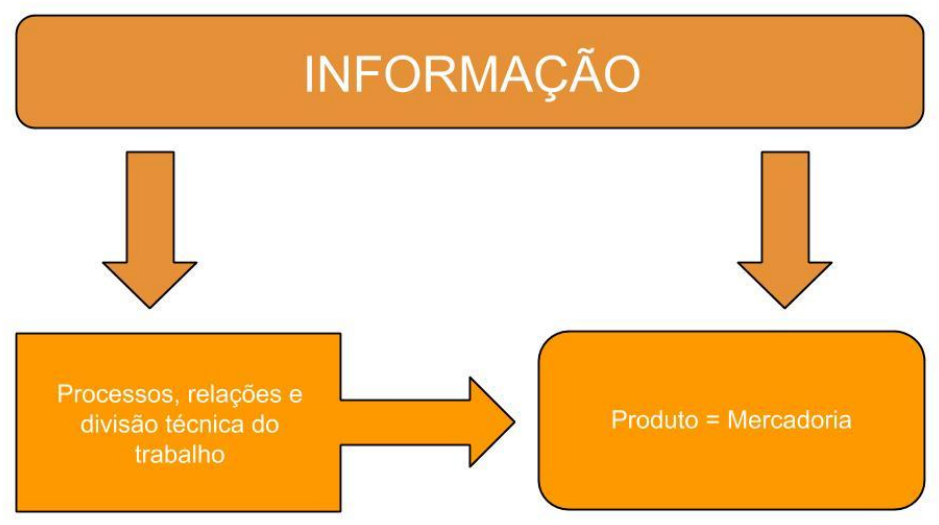

Figura 1: Ciclo do trabalho informacional

A imagem ilustra como a informação está presente e influencia em todas as etapas do processo produtivo, alterando as relações e a própria divisão técnica do trabalho, sendo ela mesma o produto, agora mercadorizada, uma commodity, inesgotável.

Procurando compreender temas que circundam o trabalho informacional, Wolf (2009) utiliza conceitos de Marx (1974) para delinear o pano de fundo em que se assenta essa forma de exploração capitalista, embora adote termos diferentes para se referir a certos fenômenos apontados por ele, por exemplo: aquilo a que Marx chama de alienação, Wolf - assim como Napoleoni, (1981, p. 90) - chamará de abstração; e a ideia por trás do termo trabalho concreto, Wolf a considerará como trabalho vivo. 
Com base nesses dois autores, pretendemos mostrar como o trabalho informacional foi reificado e os desdobramentos dessa coisificação, que se deu em três momentos, considerados por eles como sendo de alienação/abstração.

Assim, Wolf (2009) chama a atenção para o primeiro movimento de abstração, que surgiu junto com o trabalho assalariado, momento em que o trabalhador foi separado dos meios de produção e teve de começar a vender sua força de trabalho. Nesse momento histórico, decorrente do trabalho concreto, aparece o trabalho abstrato, determinado pelo tempo de trabalho socialmente necessário à produção e reprodução de mercadorias. Wolf (2009, p. 93) explica que "o trabalho abstrato é trabalho alienado, aquele que reifica, ou seja, aquele que, seguindo a lógica de produção capitalista, abstrai (aliena) as qualidades do trabalho vivo para proceder sua transformação em mercadoria (coisa)".

Quanto ao segundo movimento de abstração, Wolf (2009) destaca a inversão de posição entre homem e máquina, quando da inserção delas nos processos produtivos dentro das organizações: se antes o homem era ativo, ocupava a posição inicial no trabalho laboral, agora ele passa a ser considerado um mero instrumento. São as máquinas que detêm a complexidade do trabalho de produção das mercadorias, não sendo mais o homem quem manipula os instrumentos. Ele próprio é um intermediário que só é movimentado quando a máquina pára de funcionar por alguma razão. Para Wolf (2009, p. 95), "o advento da maquinaria otimiza em escala sem precedentes o trabalho abstrato, uma vez que concretiza a transformação da força de trabalho em meio de trabalho, consolidando, definitivamente, o modo de produção capitalista" e exercendo "um novo tipo de controle sobre o trabalho vivo".

Como havíamos comentado anteriormente, no trabalho informacional há uma alteração na divisão técnica do trabalho. Isso significa dizer que, dependendo da atuação do trabalhador em cada uma das fases do processo produtivo, haverá mais ou menos demanda por informação e conhecimento. Vendo o trabalhador como instrumento e não como executor em relação à atuação da maquinaria, que tomou a dianteira nos processos de produção, notamos aí um terceiro movimento de abstração, e talvez o mais cruel: a expropriação do saber do indivíduo, uma vez que o deslocamento do trabalhador para uma posição secundária, de coadjuvante, representa uma "separação entre trabalho e conhecimento, entre o fazer e o saber, entre concepção e execução". (WOLF, 2009, p. 95).

Dessa forma, Napoleoni (1981) argumenta que o trabalhador se torna cada vez mais distante de uma real qualificação, pois se the mostram proibitivas tanto as atividades de planejamento e concepção (frequentemente realizadas alhures) como as de execução empírica do trabalho, assumidas por uma "coisa", as máquinas.

Esses três movimentos de abstração, ou três momentos de alienação, coisificam o homem, o trabalho vivo e o trabalho informacional, revelando necessárias reflexões para que entendamos como a sociedade é afetada por mais essa faceta do Capital. Tais reflexões, originalmente realizadas dentro do campo da Sociologia do Trabalho, mostram-se igualmente necessárias aos profissionais da informação, agentes atuantes nesse "novo" modelo de trabalho informacional, pois as transformações pelas quais o mundo do trabalho vem passando são deveras relevantes para que se compreenda sua configuração atual.

Além disso, esses profissionais (da sociologia e da informação) não devem negligenciar o fato de que o mundo do trabalho está em um processo de transformação ininterrupto, observando-se o desenvolvimento cada vez mais acelerado de tecnologias que afetam o trabalho, as novas formas de organização, o surgimento e o desaparecimento de profissões, o favorecimento de inclusão e o desejável combate à exclusão, bem como a exigência cada vez maior de qualificação da mão de obra dos trabalhadores.

\section{Trabalho imaterial na tecnologia da informação e comunicação}

Com o rápido desenvolvimento e aplicação das TIC em diversos setores da economia, as mudanças organizacionais exigem um uso maior das capacidades cognitivas e comunicativas por parte dos trabalhadores. Em meados da década de 1970 surgiram algumas teses a respeito da revolução das tecnologias informacionais e o seu impacto no trabalho. Surge também o "capitalismo cognitivo", que se centra na produção de conhecimentos e informação.

Em meio a esse contexto de transformações socioeconômicas e políticas, compreende-se o trabalho imaterial, cuja definição está relacionada ao "[...] conjunto de atividades intelectuais, comunicativas, afetivas expressas 
pelos sujeitos e pelos movimentos sociais que conduzem à produção" (NEGRI, 2003, p. 92). O resultado do trabalho imaterial são produtos intangíveis, como conhecimento, informação e produtos considerados imateriais.

Castells (2000) compara a revolução da tecnologia da informação com a Revolução Industrial do século XVIII, afirmando que ambas possuem a mesma importância, pois o registro que confirma uma revolução é a penetração em todos os domínios da atividade humana. Outra característica é o fato desta revolução ter alcance a nível mundial num espaço de tempo muito curto. A partir da década de $1970 \mathrm{com}$ a flexibilização produtiva surge uma nova economia que é informacional e global. Informacional por apoiar-se e depender cada vez mais das tecnologias da informação e da comunicação - a informação não é mais apenas necessária à produção, ela própria torna-se produto - e global porque está organizada em redes de conexões entre os agentes produtivos.

A indústria sofre algumas modificações, com o aumento da produção industrial em alguns setores, como a microeletrônica, surgem outros inteiramente novos e outros deixam de existir. Assim a própria economia industrial passa por modificações se tornando também informacional e global. E de acordo com Castells (2000), como resultado líquido da primeira fase da revolução informacional observam-se vantagens e desvantagens para o progresso econômico.

No modelo pós-fordista há a centralidade do trabalho vivo no campo do intelecto, pois o trabalho do operário está cada vez mais relacionado à sua subjetividade. A reestruturação organizacional transformou o trabalho, colocando as atividades imateriais no cerne da produção industrial e terciária redefinido, principalmente, por meio da informática e da telemática, o ciclo social da produção. (LAZZARATO; NEGRI, 2001).

Com a passagem do regime de reprodução, típico do modelo fordista, para o regime de inovação que se deu principalmente com a aplicação das TIC, as atividades imateriais ganham uma relevância maior, modificando o caráter do trabalho e o padrão de acumulação de capital. Daí então surge a "economia do conhecimento", e o saber passa a ser a principal força produtiva. Em relação ao capitalismo cognitivo podemos constatar que ele opera de maneira diferenciada, a valorização é diferente do capitalismo "tradicional", pois o consumo não esgota o conhecimento diferentemente das demais mercadorias. No entanto, ao promover a apropriação e controle dos conhecimentos, limitando seu acesso, o reduze a uma mercadoria comum e semelhante às demais. (RODRIGUES, 2013).

Segundo Lazzarato e Negri (2001) as mudanças no capitalismo provocam um desuso do modelo industrial taylorista/fordista, e o conhecimento do trabalhador passa a ser a principal fonte de valorização. No entanto, no trabalho imaterial não existe uma divisão entre o "trabalho intelectual" e o "trabalho braçal", pois toda atividade requer o uso de habilidades cognitivas. É possível constatar que o trabalho imaterial é exercido por uma minoria da população trabalhadora mundial, pois a maior parte dos trabalhadores permanece exercendo atividades repetitivas, rotineiras e de certo modo consideradas desqualificadas. Ou seja, o modelo de trabalho taylorista/fordista, ainda seja muito utilizado em empresas nos países subdesenvolvidos. (POCHMMAN, 2001).

Com o crescimento do setor de serviços, o trabalho imaterial ganhou uma maior conotação. Com a imersão da área de tecnologia da informação e comunicação no mercado, surgiram novas profissões, relações de trabalho que estão mais relacionadas ao setor de serviço e ao trabalho imaterial. No desenvolvimento de softwares, por exemplo, os analistas e programadores são profissionais que se enquadram no trabalho imaterial, pois suas atividades são do tipo "intelectual" e requer qualificação específica para tal fim. (COCCO; VILARIM, 2009).

Em relação ao desenvolvimento de softwares, a participação do cliente ocorre de maneira mais ativa, pois o mesmo detém uma lista de necessidades/requisitos que deve ser atendida. Um projeto então é criado e o gerente passa a pressionar os membros (trabalhadores) para que criem soluções de acordo os requerimentos solicitados. Todo o processo é realizado com negociações, conflitos e insatisfações, pois nem sempre o software atende as existências do cliente.

De acordo com Rodrigues (2013), o software é formado por atividades como: conceituação, formalização, processamento de dados e implementação. E segue uma estrutura flexível, onde trabalhadores transitam entre as atividades de analista e de programador. Este processo de desenvolvimento é realizado por meio de decisões individuais e negociações, resistências e conflitos diretos ou indiretos entre os atores participantes, incluindo o cliente. Assim, percebe-se que os profissionais da área de desenvolvimento de software devem ter características como: ser flexível, mobilizar as habilidades cognitivas e comunicativas, estar constantemente atualizado. Contudo, esses profissionais não realizam seu trabalho de modo independente e estão sujeitos a modalidades de contrato precárias e não protegidas como os demais trabalhadores. (ROSENFIELD, 2011). 
Segundo Cocco e Vilarim (2009), as condições de produção e difusão de softwares diz respeito a quatro pontos relevantes:

1. O fato dos softwares terem se espalhado, invadindo atualmente uma série de outros dispositivos eletrônicos como os celulares, televisores, rádios e etc.

2. A característica do software em compreender, manipular e digitalizar as informações com condições de processá-las e facilitar a geração de conhecimento.

3. A produção de software está inserida na tendência de migração de atividades para os serviços; inclui as características mais significativas das atividades imateriais (colaboração, atividades simbólicas, criação de bem imaterial, etc.); gera discussões sobre como seus produtos podem ser protegidos e cerceados juridicamente.

4. Há uma grande quantidade de pessoas envolvidas na produção de software. Essa multidão engloba tanto desenvolvedores quanto usuários, tanto organizações com fins comerciais quanto grupos interessados em disseminar conhecimentos para a sociedade.

O autor ainda faz uma crítica à tentativa de aplicar o modelo fordista ao processo de desenvolvimento de software. A chegada dos microcomputadores possibilitou que mais pessoas pudessem desenvolvê-los, no entanto, a crescente produção foi se tornando desorganizada e isso levou as grandes corporações a articularem o processo para organizar a programação. Como resultado, forjou-se aos poucos um disciplinamento para a produção de software amparado em diversas técnicas, métricas e metodologias. Isso foi a base para o que se tornou a chamada engenharia de software.

Na realidade, assistiu-se aos poucos a uma disseminação de características de um modelo de produção fordista ao processo de desenvolvimento de software. Do ponto de vista da organização do trabalho, o padrão da administração científica foi disseminado na produção. O desenvolvimento do software foi fragmentado em tarefas e funções. Uma verticalização funcional cristalizou a existência de analistas, projetistas e programadores que participavam da geração do produto, mas não visualizavam necessariamente a produção do software como um todo.

Outra comparação ao modelo fordista diz respeito à "componentização" do software como um construto, tal como ocorreu com o automóvel, onde podia ser construído com peças e componentes padronizados e intercambiáveis. Isso provocou o surgimento de metodologias e técnicas capazes de permitir o desenvolvimento de software em partes preferencialmente reutilizáveis, padronizadas e independentes entre si. Um dos exemplos mais difundidos atualmente é a chamada Programação Orientada a Objetos, onde toda a solução para um problema é montada como sendo um conjunto de interações entre objetos concebidos abstratamente pelo desenvolvedor.

De acordo com Cocco e Vilarim (2009, p. 12), "a aplicação da engenharia de software, sob a forma de um conjunto de métricas e métodos que procuram a todo momento quantificar e controlar o trabalho realizado" representa a culminância deste modelo de desenvolvimento, para os tempos atuais. No entanto, essa tentativa de aplicar o modelo fordista na produção do software não se tornou hegemônica do ponto de vista do trabalho vivo, e o próprio desenvolvimento do trabalho em rede numa dinâmica horizontal, colaborativa e subjetiva, aponta para a ineficácia desse modelo de gestão.

Movimentos contrários à lógica capitalista são criados dentro do próprio sistema, como por exemplo, os movimentos mais recentes como os do software livre que têm apontado para a dimensão ilusória de um controle "industrial" do trabalho "pós-industrial".

\section{Considerações finais}

Tomando como exemplo o trabalho dos desenvolvedores e programadores de software é possível visualizar como as teorias administrativas são empregadas para extrair o máximo do trabalhador. O trabalho informacional requer criatividade, disponibilidade para troca e compartilhamento de informações, mobilização da capacidade comunicativa para incitar a subjetividade do sujeito trabalhador. 
A constante busca do trabalhador em gerar e usar informação para solucionar as incertezas e manter-se em seu posto de trabalho traz sérios prejuízos: por um lado, a velocidade e a dinâmica de trabalho provocam estresse e consequências à saúde do trabalhador; por outro, também fragiliza as relações de trabalho e dos direitos trabalhistas, já que o trabalhador informacional é submetido a contratos de trabalhos que não privilegiam direitos trabalhistas duradouros, mas somente, e apenas somente, enquanto o indivíduo for útil à organização. O novo tipo de reificação do trabalho é realizado de forma mais sutil na contemporaneidade.

Esse novo tipo de reificação é marcado pela vontade constante do capital de criar condições de manter-se independente do trabalho vivo, pois a informação e o conhecimento são transformados em dados que podem ser lidos em softwares, e assim, o transforma em trabalho morto. Contudo, diante da dinâmica do mercado e incertezas o capital precisa criar meios para estimular o trabalho vivo cada vez mais, simplificá-lo e acirrar as formas de controle sobre atividades produtivas, como estratégia de manter-se perene.

Para encerrar colocamos a reescrita do enigma da Esfinge, realizada por Wolff (2009), "se não me devorares serás devorado; se me decifrares te devorarei", ou seja, o dilema do trabalhador informacional se constitui em estar sempre a frente das demandas das organizações para manter-se em seu posto, e quando solucionar os problemas e o seu conhecimento tácito for extraído pela maquinaria, continuar criando meios de torna-se útil ainda para a organização. Um ciclo vicioso e cruel de expropriação do saber-fazer.

\section{Referências}

BEAL, A. Gestão estratégica da informação. São Paulo: Atlas, 2009.

CASTELLS, M. A Sociedade em rede. 4. ed. São Paulo: Paz e Terra, 2000. v. 1

COCCO, G.; VILARIM, G. O. Trabalho imaterial e produção de software no capitalismo cognitivo. Liinc em Revista, Rio de Janeiro, v. 5, n. 2, p. 173-190, set. 2009.

CHOO, C. W. Organização do conhecimento: como as organizações usam a informação para criar significado, construir conhecimento e tomar decisões. 2. ed. São Paulo: Senac, 2006.

DANTAS, M. Trabalho e informação: para uma abordagem dialética. Revista de Economía Política de las Tecnologías de la Informaión y Comunicación, v. 10, n. 1, ene-abr., 2010.

DAVENPORT, T. H. Ecologia da informação: porque só a tecnologia não basta para o sucesso na era da informação. 4. ed. São Paulo: Futura, 1998.

LAZZARATO, M.; NEGRI, A. Trabalho imaterial: formas de vida e produção de subjetividade. Rio de Janeiro: DP\&A, 2001.

MARX, K. O Capital. Coimbra: Centelha, 1974. Capítulo I - A mercadoria.

MAXIMIANO, A. C. M. Introdução à administração. Ed. compacta. São Paulo: Atlas, 2008.

NAPOLEONI, C. Lições sobre o capítulo VI (inédito) de Marx. São Paulo: Ciências Humanas, 1981.

NEGRI, A. Cinco lições sobre império. Trad. Alba Olmi. Rio de Janeiro: DP\&A, 2003.

POCHMANN, M. O emprego na globalização: a nova divisão internacional e os caminhos que o Brasil escolheu. São Paulo: Boitempo, 2001.

RODRIGUES, M. E. Trabalho imaterial: idealização $x$ realidade do trabalho informacional. In: SIMPÓSIO NACIONAL DE TECNOLOGIA E SOCIEDADE, 4., 2013, Curitiba. Anais... Curitiba: [s.n.], 2013.

ROSENFIELD, C. L. Autonomia no trabalho informacional: liberdade ou controle? In: PICCINI, V. C. et al (Org.). O mosaico do trabalho na sociedade contemporânea: persistência e inovações. Editora da UFRGS: Porto Alegre, 2006.

Trabalho decente e justificação da precarização. Revista Tempo Social, São Paulo, v. 23, n. 1, p. 1-23, jun. 2011.

TENÓRIO, F. G. Gestão de ONGs: principais funções gerenciais. 11. ed. Rio de Janeiro: FVG, 2009.

WOLFF, S. O "trabalho informacional" e a reificação da informação sob os novos paradigmas organizacionais. In: ANTUNES, R.; BRAGA, R. (Org.). Infoproletários: degradação real do trabalho virtual. São Paulo: Boitempo: 2009. p. 89-112. 


\section{Dados dos autores}

\section{Edilene Maria da Silva}

Doutoranda em Ciência da informação pela Universidade Federal da Paraíba - UFPB (2012-) com a temática do projeto-tese relativa à Gestão da informação no setor público. Mestra em Ciëncia da Informação pela UFPB (2009), com Especialização em Gestão da Informação (2006) e formação em Biblioteconomia pela Universidade Federal de Pernambuco - UFPE (2002). É professora do Departamento Ciência da Informação da UFPE. Tem interesse nas seguintes áreas: Política de informação, Gestão da informação, Gestão de unidade de informação, Indicadores de desempenho, indicadores de C\&T, Ética e responsabilidade social, memória científica e tecnológica e repositório institucional.

dilemabr@gmail.com

\section{Hamilton Rodrigues Tabosa}

Doutorando do Programa de Pós-Graduação em Ciência da Informação da Universidade Federal da Paraíba. Mestre em Avaliação de Políticas Públicas, Especialista em Gestão Universitária e Bacharel em Biblioteconomia pela Universidade Federal do Ceará (UFCE). Atualmente é Professor Assistente do curso de Bacharelado em Biblioteconomia da UFC. Foi Coordenador de Estágios Curriculares do Curso de Biblioteconomia da UFC de 2009 a 2011. Orienta estágios curriculares e monografias na Graduação em Biblioteconomia e na Especialização em Tecnologias Aplicadas ao Tratamento, Recuperação e Gestão da Informação da UFC. Possui experiência em bibliotecas escolares e universitárias, com ênfase no Serviço de Referência, em processos de disseminação seletiva da informação, representações descritiva e temática e recuperação da informação. Áreas de interesse: Biblioteca Universitária, Biblioteca Especializada, Gestão e Representação da informação, comportamento informacional, fontes de informação, acessibilidade informacional, tecnologias da informação e da comunicação.

hrtabosa@gmail.com

\section{Williams Santos}

Mestrando do Programa de Pós-Graduação em Ciência da Informação da Universidade Federal da Paraíba (UFPB). williamspsantos@gmail.com

\section{Edvaldo Carvalho Alves}

Possui Graduação em Ciências Sociais pela Universidade Federal da Paraíba (2000), Mestrado em Ciências Sociais pela Universidade Federal de São Carlos (2002) e Doutorado em Ciências Sociais pela Universidade Federal de São Carlos (2007). Atualmente é Professor Adjunto IV do Departamento de Ciência da Informação DCI/ UFPB e do Programa de Pós-Graduação em Ciência da Informação - PPGCI/UFPB. Tem experiência na área de Sociologia, atuando principalmente nos seguintes temas: Sociologia da Informação, Sociabilidades, identidade e memória na sociedade contemporânea, Estudo do usuário. Estudos Culturais em Informação.

\section{edvaldocalves@gmail.com}

Recebido - Received : 2014-05-17

Aceitado - Accepted : 2015-03-30

\section{(c)) EY}

This work is licensed under a Creative Commons Attribution 4.0

United States License.

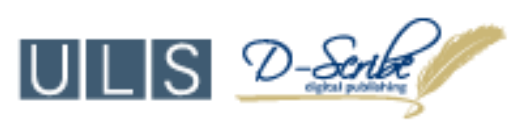

This journal is published by the University Library System of the University of Pittsburgh as part of its D-Scribe Digital Publishing Program and is cosponsored by the University of Pittsburgh Press. 